\title{
Precipitants of Constipation During Early Childhood
}

Stephen M. Borowitz, MD, Daniel J. Cox, PhD, Anita Tam, Lee M. Ritterband, PhD, James L. Sutphen, MD, PhD, and J. Kim Penberthy, PhD

Background: Childhood constipation is a common problem, accounting for $3 \%$ of visits to pediatric clinics and $30 \%$ of visits to pediatric gastroenterologists. Estimates of the prevalence of childhood constipation vary from $0.3 \%$ to $28 \%$ with younger children being affected most often. We were unable to find any studies that specifically examine the causes of constipation in young children. Our objective of the study was to determine precipitants to constipation during early childhood.

Methods: Findings from 125 families visiting their primary care physician for the first time with a child aged between 2 and 7 years with the complaint of constipation were compared with findings from 95 children between 2 and 7 years without any history of constipation. Parents answered questions concerning family history, toilet training, and bowel habits. Parents of constipated children were asked to describe events that occurred during the 3 months before the onset of constipation and whether these events contributed to the child's constipation

Results: The age and sex of children who did and did not suffer from constipation were comparable $(P>.3)$. When compared with control children, constipated children were no more likely to have a parent $(30 \%$ vs $40 \%, P=.14)$ or sibling $(17 \%$ vs $14 \%, P=.54)$ with a history of constipation. Constipated children did not begin toilet training earlier than did control children $(28 \pm 7$ vs $27 \pm 6$ months, $P=.30)$. When compared with parents of control children, parents of constipated children reported more difficulties with toilet training $(P<.001)$. Parents of constipated children indicated their children had more difficult and more painful defecation experiences than did parents of control children $(P<$ .001 ), and constipated children were more likely to express worry about future painful defecation than were control children $(P<.001)$. Parents of constipated children described a number of events that occurred before the onset of constipation; however, they did not consider many of the events important contributors to the constipation. Painful defecation was the event most often reported as causing the constipation.

Conclusion: Painful defecation is the primary precipitant of constipation during early childhood. Parents should be counseled to be attentive to such experiences and taught to intervene quickly to lessen the risk that their child will develop persistent constipation or fecal soiling. ( $\mathrm{J}$ Am Board Fam Pract 2003;16:213-8.)

Childhood constipation is an extremely common problem that accounts for $3 \%$ of visits to general pediatric clinic and as much as $30 \%$ of visits to pediatric gastroenterologists. ${ }^{1}$ Estimates of the worldwide prevalence of childhood constipation vary widely from $0.3 \%$ to $28 \%$, with younger children being affected most often. ${ }^{2-4}$ Sixteen percent of parents of 22-month-old children report consti-

Submitted, revised, 24 July 2002.

From the Departments of Pediatrics (SMB, JLS) and Behavioral Medicine (DJC, AT, LMR, JKP), University of Virginia Health Sciences Center, Charlottesville. Address reprint requests to Stephen $M$. Borowitz, MD, Division of Pediatric Gastroenterology, Box 800386 HSC, University of Virginia Health Sciences Center, Charlottesville, VA 22908.

This research report was supported by NIH grant RO1 HD 28160. pation in their children, ${ }^{5} 34 \%$ of British children 4 to 11 years of age have been constipated, and $5 \%$ experience chronic constipation lasting more than 6 months. $^{6}$

Little research has focused on the underlying causes and natural history of constipation during early childhood. ${ }^{7}$ In a recent review of the literature on pediatric constipation, ${ }^{8}$ we were able to find only two studies investigating the treatment of constipation among preschool-aged children. ${ }^{2,9}$ These two studies were single-group, uncontrolled studies. We were unable to find any studies that specifically examined the causes of constipation in young children.

We investigated these issues by surveying both parents whose children came to their primary care 


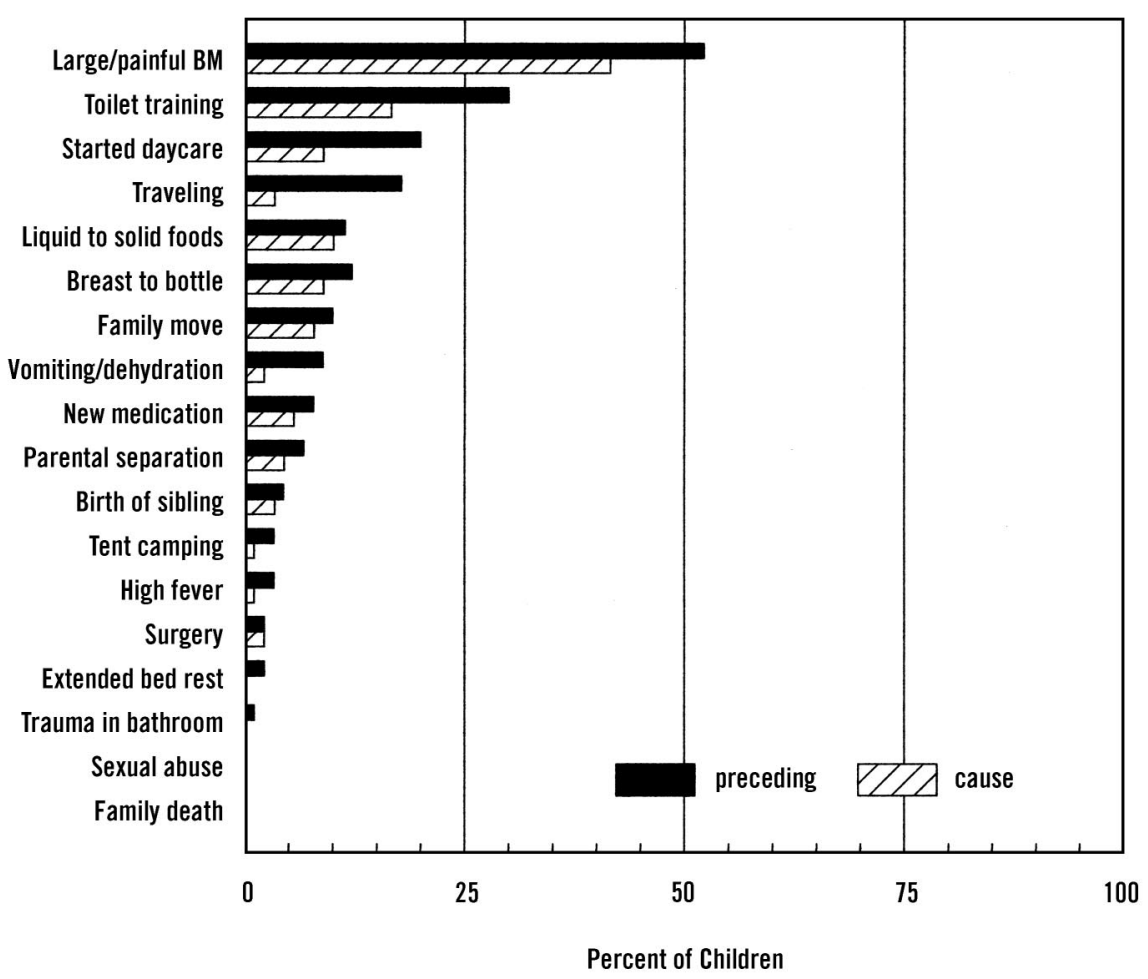

Figure 1. Parent-described events that occurred within 3 months of onset of child's constipation (solid bars), and events they believed caused child's constipation (striped bars). BM - bowel movement.

physician for the first time with a complaint of constipation and parents whose children had never experienced constipation. Using these groups allowed us to determine precipitants of constipation, not only early in the sequence of events before early treatment responders were weeded out but also before constipation became a chronic problem.

\section{Methods \\ Participants}

We recruited 125 children who were visiting their primary care physician for the first time with a chief complaint of constipation. These children were recruited from 26 primary care facilities throughout central Virginia (15 pediatricians and 11 family physicians). When parents first contacted the primary care physician about their child's constipation, the parents were informed of the study by the office staff. Parents who expressed interest in the study were contacted by the research team and given additional details about the study. Children were eligible for the study if they were between the ages of 2 years 0 months and 6 years 11 months, were coming to a physician for the first time with the complaint of constipation, had no underlying physical condition and were taking no medication that could account for their constipation, and were of at least average intelligence. For purposes of the study, constipation was defined as the passage of fewer than three bowel movements each week for at least 2 consecutive weeks. ${ }^{2,10,11}$

Twenty-two nonconstipated patient siblings were recruited as controls at the time that their siblings were recruited. An additional 73 nonsibling control children were recruited through newspaper articles and television advertisements. Control children were also between ages 2 years 0 months and 6 years 11 months, had at least average intelligence, and had no history of constipation.

The Human Investigation Committee at the University of Virginia approved the study protocol, and informed consent was obtained for all participants.

\section{Experimental Procedure}

At the time of enrollment, all parents were given a questionnaire containing items describing children's bowel habits. The parents of patients were also provided with a list of 18 different events (Figure 1) and asked to indicate which (if any) of 
Table 1. Demographic Characteristics of Constipated and Nonconstipated Control Children.

\begin{tabular}{|c|c|c|c|}
\hline Variable & $\begin{array}{l}\text { Constipated } \\
(\mathrm{n}=125)\end{array}$ & $\begin{array}{l}\text { Control } \\
(\mathrm{n}=95)\end{array}$ & $P$ value \\
\hline Age (mo) & $44 \pm 13$ & $46 \pm 18$ & .36 \\
\hline $\begin{array}{l}\text { Sex }(\%) \\
\text { Male } \\
\text { Female }\end{array}$ & $\begin{array}{l}49 \\
51\end{array}$ & $\begin{array}{l}54 \\
46\end{array}$ & .96 \\
\hline $\begin{array}{l}\text { Family history of constipation } \\
\text { Parents } \\
\text { Siblings }\end{array}$ & $\begin{array}{l}30 \\
17\end{array}$ & $\begin{array}{l}40 \\
14\end{array}$ & $\begin{array}{l}.14 \\
.56\end{array}$ \\
\hline Age toilet training began (mo) & $28 \pm 7$ & $27 \pm 6$ & .24 \\
\hline $\begin{array}{l}\text { Degree of difficulty with toilet training } \\
\quad(0=\text { none, } 4=\text { extreme })\end{array}$ & $2.1 \pm 1.3$ & $1.4 \pm 1.1$ & $<.001$ \\
\hline \multicolumn{4}{|l|}{$\begin{array}{l}\text { Degree of difficulty passing some bowel } \\
\text { movements (\%) }\end{array}$} \\
\hline $\begin{array}{l}\text { None } \\
\text { Mild } \\
\text { Moderate } \\
\text { Extreme }\end{array}$ & $\begin{array}{r}3 \\
86 \\
80 \\
76\end{array}$ & $\begin{array}{r}49 \\
49 \\
10 \\
5\end{array}$ & $\begin{array}{l}<.001 \\
<.001 \\
<.001 \\
<.001\end{array}$ \\
\hline \multicolumn{4}{|l|}{$\begin{array}{l}\text { Degree of pain passing some bowel } \\
\text { movements }(\%)\end{array}$} \\
\hline $\begin{array}{l}\text { None } \\
\text { Mild } \\
\text { Moderate } \\
\text { Severe }\end{array}$ & $\begin{array}{r}5 \\
82 \\
69 \\
67\end{array}$ & $\begin{array}{r}56 \\
40 \\
8 \\
6\end{array}$ & $\begin{array}{l}<.001 \\
<.001 \\
<.001 \\
<.001\end{array}$ \\
\hline $\begin{array}{l}\text { Children expressing worry about passing } \\
\text { bowel movements (\%) }\end{array}$ & 75 & 8 & $<.001$ \\
\hline
\end{tabular}

these events occurred within the 3 months before the onset of the constipation. The parents were asked to indicate which of these events they believed contributed to the development of their child's constipation. Parents were also asked how difficult toilet training for bowel movements had been using a Likert scale from 0 to 4 , with 0 being not at all difficult and 4 being extremely difficult.

\section{Data Analysis}

Categorical variables were compared using chisquare analysis. Continuous variables were compared using unpaired 2-tailed $t$ tests. Differences were considered statistically significant when $P<$ .05. All data are presented as mean plus or minus standard deviation of the mean unless stated otherwise.

\section{Results}

The demographic characteristics of the constipated children and control children are summarized in Table 1 . The average age at onset of symptoms in the constipated children was $27 \pm 17$ months. The two groups were comparable in age ( $44 \pm 13$ mo vs $46 \pm 18 \mathrm{mo}, P=.36)$ and sex (49\% male vs $54 \%$ male, $P=.96)$.
When compared with nonconstipated nonsibling control children, constipated children were no more likely to have a parent ( $30 \%$ vs $40 \%, P=.14$ ) or a sibling $(17 \%$ vs $14 \%, P=.56)$ with a history of constipation. Similarly, constipated children did not begin toilet training any earlier than did control children $(28 \pm 7$ mo vs $27 \pm 6$ mo, $P=.30$ ). Using a Likert scale ranging from 0 to 4 , with 0 being not at all difficult and 4 being extremely difficult, parents of constipated children reported more difficulty with toilet training than did parents of control children (mean score $2.1 \pm 1.3$ vs $1.4 \pm$ $1.1, P<.001)$. Parents of constipated children indicated that their children had more difficult and more painful defecation experiences than did control children $(P<.001)$, and the constipated children were more likely to express worry about future painful defecation than were the control children (75\% vs $8 \%, P<.001)$. These results are summarized in Table 1.

Although parents of constipated children reported a number of events that occurred during the 3 months before the development of their child's constipation, they did not consider many of the events important contributors to the development of their child's constipation. There was, however, 


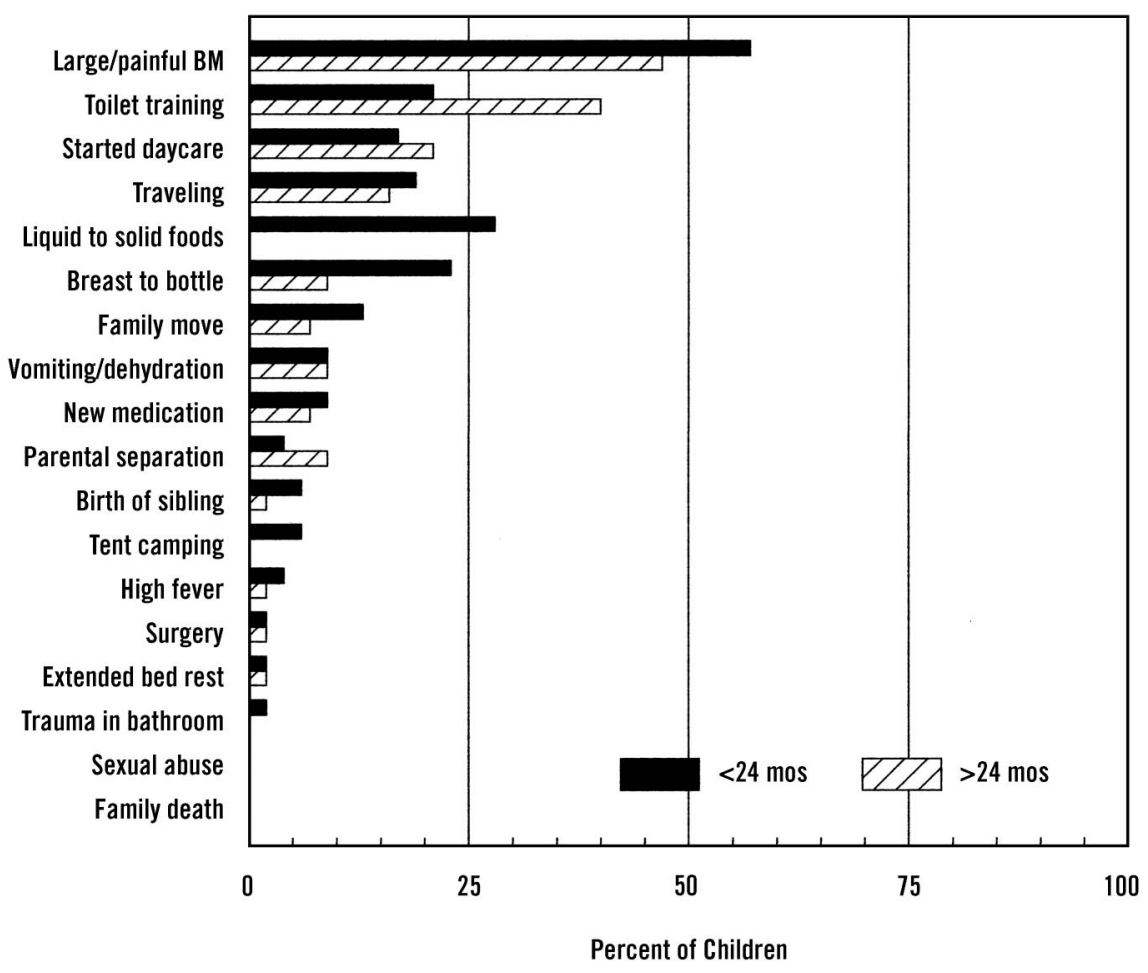

Figure 2. Events parents said occurred during the 3 months before child's constipation, and children $(n=125)$ grouped according to whether constipation started before (solid bars) or after (striped bars) the child's second birthday. BM - bowel movement.

general agreement between the frequency of events and their causal attribution $(\mathrm{r}=.94, P<.001)$. Painful defection was by far the event most commonly reported before the onset of constipation, as well as the event most often described as causing constipation. For 65 of the 125 families (52.2\%), passage of a large or painful bowel movement was reported before the onset of constipation, and 52 of these 65 families (80\%) reported the passage of a large or painful bowel movement as the cause of their child's constipation. Toilet training was the second most frequently reported precipitant of constipation (21 families, or $16.7 \%$ ).

Relatively few parents reported the birth of a sibling or a surgical procedure having occurred within 3 months of the onset of constipation, but when these events were described, they were almost always considered precipitants for the development of constipation by these parents. Severe psychological factors, such as trauma in the bathroom, sexual abuse, and death of a family member, were infrequent events and were never described as major contributing factors to the development of constipation. These results are summarized in Figure 1.
We grouped constipated children according to whether they became constipated before or after their second birthday (median split). The events parents reported having occurred in the 3 months before the onset of constipation were similar in the two groups, with the exception of toilet training having occurred more often before constipation in the older children, and making the dietary transition from breast to bottle and from liquid to solid diets having occurred more often before constipation in the younger children (Figure 2). When we compared perceived causal events, large or painful bowel movements were by far the most frequent precipitating event for both age groups. Toilet training was seen as more of a precipitant for olderonset children, whereas transition from breast to bottle and from liquid to solid foods was seen to be more of a problem for younger-onset children (Figure 3).

\section{Discussion}

A variety of factors have been proposed as precipitants of constipation during early childhood, in- 


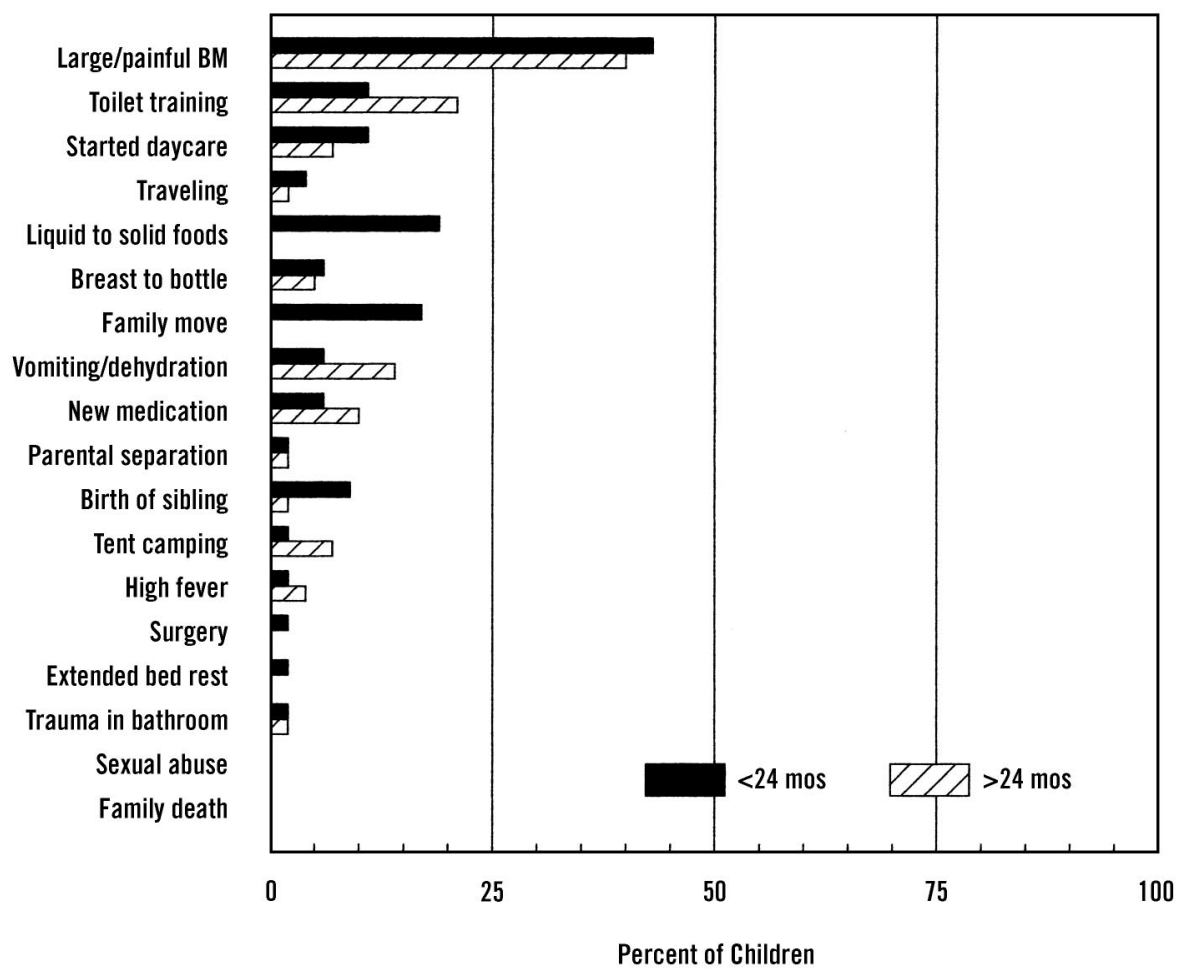

Figure 3. Events parents believed caused child's constipation, and children $(n=125)$ grouped according to whether constipation started before (solid bars) or after (striped bars) the child's second birthday. BM - bowel movement.

cluding a genetic predisposition, ${ }^{12}$ beginning toilet training too early or having difficulty with toilet training, ${ }^{13}$ dietary transitions from breast milk to formula ${ }^{14}$ or from liquid to solid foods, ${ }^{15}$ having painful or difficult bowel movements, ${ }^{16}$ beginning school, ${ }^{17}$ or a traumatic bathroom experience. ${ }^{18}$ Until now, there has been no research examining the frequency and importance of such events.

Between 1958 and 1986, the number of physician visits for children aged 0 to 9 years attributed to constipation doubled, and most of this increase occurred in children younger than 2 years. ${ }^{1,3}$ It is unclear whether this increase reflects an increase in childhood constipation or a greater likelihood that parents will seek medical attention when their child experiences constipation. Some authors have attributed this apparent increase in childhood constipation to changing patterns in toilet training. ${ }^{3}$ Others have hypothesized that constipation is becoming more widespread because of the diminished dietary intake of fiber associated with modern foodprocessing methods. ${ }^{19}$

Our data indicate that in most cases young children develop constipation as a result of experienc- ing pain with defecation rather than as a result of external factors, such as family history, age of toilet training, or other forms of physical or psychological trauma. We have previously shown that the timing, style, and techniques used during toilet training are not associated with the development of early childhood constipation. ${ }^{20}$ In the current study, when parents were asked to describe factors that occurred within 3 months of the onset of the child's constipation and that they believed might have contributed to the development of constipation, they overwhelmingly reported painful defecation as a causal factor. Factors beyond the control of the parents, such as medication usage, sexual abuse, death of a family member, or high fever, occurred infrequently and were rarely described as causes of constipation.

Although most young children suffering from acute constipation do not develop chronic constipation, $5 \%$ of children aged 4 to 11 years experience constipation lasting more than 6 months, ${ }^{6}$ and more than $50 \%$ of school-aged children with fecal soiling or chronic fecal impaction have a history of painful defecation before 26 months of age. ${ }^{1}$ Pre- 
liminary evidence suggests that aggressive management shortly after constipation develops lessens the likelihood of chronic constipation, ${ }^{20}$ yet primary care physicians are not very effective in managing constipation in young children, treating it successfully only one half the time. ${ }^{20,21}$ The findings of this study suggest families should be provided with guidance and recommendations about prevention, early recognition, and early intervention of constipation in young children so that the child will be less likely to develop chronic constipation or fecal soiling. Parents should be counseled to watch for infrequent, difficult, or painful defecation, and when they observe it, to respond promptly by encouraging the child to attend the toilet more frequently, modifying the child's diet, or using an osmotic laxative. ${ }^{8}$ Parents should also be counseled to be vigilant for signs of constipation during toilet training, while on family vacations, in the event of relocation, or when the child starts school.

\section{References}

1. Partin JC, Hamill SK, Fischel JE, Partin JS. Painful defecation and fecal soiling in children. Pediatrics 1992;89(6 Pt 1):1007-9.

2. Loening-Baucke V. Constipation in early childhood: patient characteristics, treatment, and long-term follow up. Gut 1993;34:1400-4.

3. Sonnenberg A, Koch TR. Physician visits in the United States for constipation: 1958 to 1986. Dig Dis Sci 1989:34:606-11.

4. de Araujo Sant'Anna AM, Calcado AC. Constipation in school-aged children at public schools in Rio de Janeiro, Brazil. J Pediatr Gastroenterol Nutr 1999; 29:190-3.

5. Isenmann RM, Hewson S, Pirhonen D, Tylor W, Tirosh A. Are chronic digestive complaints the result of abnormal dietary patterns? Am J Dis Child 1987; 141:679-82.

6. Yong D, Beattie RM. Normal bowel habit and prevalence of constipation in primary-school children. Ambul Child Health 1998;4:277-82.
7. Stark LJ. Treatment of encopresis: where do we go from here? J Pediatr Psychol 2000;25:255-6.

8. Brooks RC, Copen RM, Cox DJ, Morris J, Borowitz S, Sutphen J. Review of the treatment literature for encopresis, functional constipation, and stooltoileting refusal. Ann Behav Med 2000;22:260-7.

9. Luxem MC, Christophersen ER, Purvis PC, Baer DM. Behavioral-medical treatment of pediatric toileting refusal. J Dev Behav Pediatr 1997;18:34-41.

10. Loening-Baucke V. Chronic constipation in children. Gastroenterology 1993;105:1557-64.

11. Baker SS, Liptak GS, Colletti RB, et al. Constipation in infants and children: evaluation and treatment. A medical position statement of the North American Society for Pediatric Gastroenterology and Nutrition. J Pediatr Gastroenterol Nutr 1999;29:612-26.

12. Goulet O, Jobert-Giraud A, Michel JL, et al. Chronic intestinal pseudo-obstruction syndrome in pediatric patients. Eur J Pediatr Surg 1999;9:83-9.

13. Polanco I, Prieto G. Functional constipation. Semin Pediatr Gastroenterol Nutr 1992;3:8-10.

14. Lloyd B, Halter RJ, Kuchan MJ, Baggs GE, Ryan AS, Masor ML. Formula tolerance in postbreastfed and exclusively formula-fed infants. Pediatrics 1999; 103:E7.

15. Becker M, Rosskamp R. [Therapy of constipation with wheat bran in infancy and early childhood.] Monatsschr Kinderheilkd 1987;135:522-4.

16. Loening-Baucke V. Functional constipation. Semin Pediatr Surg 1995;4:26-34.

17. Leung AK, Chan PY, Cho HY. Constipation in children. Am Fam Physician 1996;2:611-8, 627.

18. Lewis A, Hillemeier C. Pediatric constipation: diagnosis and therapy. In Pediatric Gastrointestinal Disorders. City: Publisher, 1989:31-4, 39, 67-8.

19. Petticrew M, Watt I, Sheldon T. Systematic review of the effectiveness of laxatives in the elderly. Health Technol Assess 1997;1:1-52.

20. Borowitz SM, Brooks R, Kovatchev B, Ritterband L, Sutphen JL, Cox DJ. Constipation in early childhood: precipitating factors and treatment outcome. Pediatr Res 1999; 45:109A.

21. Penberthy JK, Cox DJ, Kovatchev B, et al. Treatment efficacy for pediatric constipation. Washington, DC: American Psychological Association, 2000. 